\title{
VALUASI EKONOMI OBJEK WISATA KAWASAN PANTAI BARON GUNUNG KIDUL APLIKASI TRAVEL COST METHOD
}

\author{
Hendro Wibowo \\ Universitas Padjadjaran Bandung \\ hendro19001@mail.unpad.ac.id
}

\section{Diterima: November 2020; Disetujui: Maret 2021}

\begin{abstract}
The Baron Beach Area is one of the favorite beach attractions with the highest number of visitors in Gunung Kidul Regency. However, the presence of coastal abrasion and decreasing environmental quality needs to be a concern for the management. Understanding of the economic value and visitor characteristics is important for management considerations in a more optimal and effective coastal management. Economic valuation is an important instrument for estimating the monetary value of benefits and changes in benefits obtained by humans from natural resources, such as beaches. This study aims to estimate the economic value of the Baron Beach Area using the Individual Travel Cost Method. The variables used are travel cost (TC), expenditure (EXPEND), age (AGE), education level (EDU), other tourist object substitution dummy $(D S)$, and environmental quality dummy (DENVR). This count data study used the negative binomial regression method. The results showed consumer surplus per person per visit was IDR 282,531.00 and total economic value of the Baron Beach Area was IDR 560,182,653,564.00 per year.
\end{abstract}

Keyword: baron beach, economic valuation, negative binomial regression, travel cost method.

Abstraksi. Kawasan Pantai Baron merupakan salah objek wisata pantai favorit dengan jumlah pengunjung terbanyak di Kabupaten Gunung Kidul. Namun adanya abrasi pantai dan kualitas lingkungan yang semakin menurun perlu menjadi perhatian bagi pihak pengelola. Pemahaman terhadap nilai ekonomi dan karakteristik pengunjung penting untuk bahan pertimbangan manajemen dalam pengelolaan kawasan pantai yang lebih optimal dan efektif. Penilaian ekonomi merupakan salah satu instrumen penting untuk menaksir nilai moneter dari manfaat maupun perubahan manfaat yang diperoleh manusia dari suatu sumber daya alam, seperti pantai. Penelitian ini bertujuan untuk mengestimasi nilai ekonomi Kawasan Pantai Baron dengan menggunakan Individual Travel Cost Method. Variabel yang digunakan yaitu travel cost (TC), pengeluaran (EXPEND), usia $(A G E)$, tingkat pendidikan (EDU), dummy substitusi objek wisata lain (DS), dan dummy kualitas lingkungan (DENVR). Penelitian count data ini menggunakan metode negative binomial regression. Hasil penelitian menunjukkan surplus konsumen per orang per kunjungan sebesar Rp282.531,00 dan total nilai ekonomi Kawasan Pantai Baron sebesar Rp560.182.653.564,00 per tahun.

Kata Kunci: pantai baron, penilaian ekonomi, regresi negatif binomial, travel cost method.

\section{PENDAHULUAN}

Kabupaten Gunung Kidul secara geografis adalah kabupaten yang berhadapan langsung dengan Samudera Indonesia. Potensi wisata pantai di Gunung
Kidul membentang sepanjang wilayah selatan dengan panjang pesisir pantai sekitar $70 \mathrm{Km}$ dan luas wilayah sekitar 300 Ha (BPS Gunung Kidul, 2018). Kawasan Pantai Baron merupakan objek wisata 
pantai favorit dengan jumlah kunjungan terbanyak di Kabupaten Gunung Kidul yaitu sekitar 2.047.168 pengunjung pada tahun 2018. Kawasan Pantai Baron berada di Desa Kemadang, Kecamatan Tanjung Sari, Kabupaten Gunung Kidul. Kawasan pantai ini menjadi favorit pengunjung karena memiliki hamparan pasir pantai yang cukup luas dan memiliki fasilitas yang cukup lengkap yaitu adanya tempat pelelangan ikan, penginapan, tempat wisata kuliner seafood. Keunikan yang dimiliki Kawasan Pantai Baron yaitu adanya sungai bawah tanah yang berada di dekat bibir pantai dan bermuara ke arah laut serta adanya gardu pandang di area bukit pantai.

Sektor pariwisata menyumbang sekitar 12 persen bagi Pendapatan Asli Daerah (PAD) di Kabupaten Gunung Kidul pada tahun 2017, namun dalam beberapa tahun terakhir target PAD dari pemerintah tidak tercapai karena adanya penurunan wisatawan yang berkunjung di Kabupaten Gunung Kidul. Penurunan jumlah kunjungan yang terjadi di Kawasan Pantai Baron disebabkan adanya berbagai macam permasalahan di antaranya pencemaran di area sekitar pantai yang disebabkan oleh sampah-sampah wisatawan dan kegiatan di tempat pelelangan ikan serta adanya genangan air di seluruh area parkir yang disebabkan oleh ketidakteraturan kemiringan permukaan. Selain itu, ancaman serius lainnya yaitu adanya abrasi di area bibir pantai yang menyebabkan daya tampung pengunjung menjadi semakin berkurang (Pamungkas, 2018).

Menurut Zhang et al., (2015), perlu adanya pemahaman mengenai karakteristik dari pengunjung dan penilaian terhadap benefit ekonomi yang diperoleh dari suatu situs rekreasi. Penilaian tersebut dapat menjadi bahan pertimbangan bagi para pengambil kebijakan mengenai apa yang harus dilakukan dan berapa yang harus diinvestasikan untuk mempertahankan keberadaan suatu situs wisata.

Penilaian ekonomi memungkinkan untuk mengestimasi nilai moneter dari manfaat ataupun perubahan manfaat yang didapatkan manusia dari suatu ekosistem dengan pendekatan indikator-indikator yang diukur dalam satuan moneter (Marre et al., 2016). Penilaian ekonomi dapat digunakan untuk menilai dampak dari suatu aktivitas terhadap kekayaan alam (aset) baik yang dapat memberikan benefit (manfaat) maupun yang menjadi beban atau biaya. Apabila nilai manfaat ekonomi yang dihasilkan oleh sumber daya alam dan ekosistem lebih besar dari biayanya, maka dapat menjadi pertimbangan untuk mendukung tindakan untuk perlindungan dan pelestarian objek tersebut. Penilaian ekonomi dapat menjadi instrumen penting yang dapat mempengaruhi pengambilan keputusan pemerintah, sosial, individu, dan kolektif (Zambrano-Monserrate et al., 2018).

Tujuan dari penelitian ini yaitu untuk mengetahui nilai ekonomi dari Kawasan Pantai Baron dengan menggunakan Individual Travel Cost Method (ITCM). Studi ini menggunakan variabel biaya perjalanan, pengeluaran individu, tingkat pendidikan, usia, substitusi objek wisata lain, dan persepsi kualitas lingkungan untuk menjelaskan pengaruhnya dalam jumlah kunjungan individu ke Kawasan Pantai Baron. Penelitian ini diharapkan dapat memperkaya literatur penilaian ekonomi objek wisata dengan menggunakan metode biaya perjalanan, sebagai bahan masukan 
bagi pihak pengelola maupun pemerintah dalam meningkatkan potensi wisata dan sumber daya lingkungan di Kawasan Pantai Baron.

\section{METODE PENELITIAN}

\section{Travel Cost Method}

Objek wisata alam dan pantai merupakan fasilitas publik yang tidak diperjualbelikan dan tidak mempunyai nilai pasar. Salah satu metode yang dapat digunakan untuk mengestimasi nilai suatu barang/jasa yang tidak memiliki nilai pasar yaitu dengan Travel Cost Method (TCM) (Zhang et al., 2015). TCM merupakan salah satu metode penilaian ekonomi tidak langsung yang berbasis permintaan untuk mengestimasi nilai guna situs-situs rekreasi. Metode ini telah banyak digunakan untuk menaksir nilai-nilai ekonomi yang berhubungan dengan ekosistem sumber daya alam seperti taman, pantai, hutan alam, sungai yang digunakan untuk memancing, atau area lain di mana rekreasi outdoor berlangsung (Parsons, 2003). Semua biaya (baik berupa uang maupun waktu) yang dikeluarkan oleh wisatawan untuk mengakses situs rekreasi tertentu dapat digunakan untuk mengukur berapa nilai dari situs rekreasi yang dikunjungi tersebut (Zambrano-Monserrate et al., 2018).

Terdapat dua bentuk TCM, yaitu Zonal Travel Cost Method (ZTCM) dan Individual Travel Cost Method (ITCM). Pengukuran nilai situs rekreasi suatu area dengan menggunakan ZTCM dengan mengalikan average cost yang dikeluarkan selama berkunjung ke suatu zona dengan jumlah total kunjungan di suatu daerah atau zona tersebut (Zhang et al., 2015). Pengukuran nilai situs rekreasi dengan ITCM dengan memperhitungkan biaya (misalnya biaya perjalanan, biaya waktu, biaya tiket masuk wisata, biaya perlengkapan berwisata) yang dikeluarkan oleh individu dalam aktivitas rekreasi tersebut (Ariza et al., 2012) dengan mempertimbangkan karakteristik sosialekonomi dari masing-masing individu seperti pendapatan, tingkat pendidikan, jenis kelamin, dan usia (Zhang et al., 2015).

\section{Data}

Penelitian ini menggunakan data primer dan data sekunder. Data sekunder diperoleh dari publikasi Dinas Pariwisata Provinsi Daerah Istimewa Yogyakarta dan Dinas Pariwisata Kabupaten Gunung Kidul. Data primer diperoleh dari wawancara melalui kuesioner kepada pengunjung objek wisata Kawasan Pantai Baron dari tanggal 11 Agustus s.d. 6 September 2020. Survei ditujukan kepada orang dewasa (18 tahun atau lebih) di mana satu orang per kelompok dipilih secara acak untuk mengisi kuesioner.

Teknik pengambilan sampel yaitu menggunakan purposive sampling. Jumlah responden yang ditemui yaitu sebanyak 238 orang namun tidak semua responden bersedia untuk mengisi item pertanyaan dalam kuesioner. Jumlah data yang dinyatakan lengkap dan dapat dianalisis lebih lanjut yaitu sebanyak 206 data.

\section{Regresi Count Data}

Dengan menganalisis hubungan pengaruh biaya perjalanan (price) yang dikeluarkan untuk mengakses wisata pantai terhadap jumlah kunjungan per tahun (quantity), maka diperoleh kurva permintaan. Secara umum, kurva permintaan berbentuk downward, yaitu semakin tinggi biayanya, semakin sedikit jumlah kunjungan (Pyndyck \& Rubinfeld, 2013). Untuk menganalisis hubungan pengaruh biaya perjalanan terhadap jumlah kunjungan per tahun, maka metode regresi dapat digunakan. 
Model regresi poisson lebih tepat digunakan untuk mengestimasi model daripada OLS karena karakteristik dari variabel dependennya (jumlah kunjungan wisatawan) adalah data diskrit dengan bilangan bulat non negatif (Haab \& McConnell, 2002). Namun masalah yang sering dialami dalam model poisson dengan data diskrit yaitu adanya overdispersi (overdispersion) di mana nilai varians yang dihasilkan lebih besar dari nilai mean. Overdipsersi pada model yang menggunakan count data memiliki konsekuensi yang serius terhadap hasil estimasi dan inferensi (Grogger \& Carson, 1991).

Dalam kondisi overdispersi maka model poisson ditolak dan model negative binomial regression lebih tepat untuk digunakan. Menurut Zhang et al., (2015) model permintaan dengan negative binomial regression untuk situs rekreasi dapat dituliskan sebagai berikut.

$\mathrm{E}\left(\mathrm{y}_{\mathrm{i}} \mid \mathrm{x}_{\mathrm{i}}\right)=\exp (\beta \cdot \mathrm{x})$

$\mathrm{E}\left(\mathrm{y}_{\mathrm{i}} \mid \mathrm{x}_{\mathrm{i}}\right)=\exp \left(\beta_{0}+\beta_{1} \mathrm{TC}_{\mathrm{i}}+\beta_{2} \mathrm{EXP}_{\mathrm{i}}+\right.$ $\beta_{3} \mathrm{AGE}_{\mathrm{i}}+\beta_{4} \mathrm{EDUC}_{\mathrm{i}}+\beta_{5}$ DSUBT $_{i}+\beta_{6}$ QENV $\left._{i}+\varepsilon_{i}\right)$..

Definisi operasional variabel dari persamaan di atas yaitu sebagai berikut:

$\mathrm{y} \quad=$ jumlah kunjungan individu $\mathrm{ke}$ Kawasan Pantai Baron per individu selama 1 tahun

$\mathrm{TC}_{\mathrm{i}}=$ biaya perjalanan yang dikeluarkan pengunjung selama perjalanan wisata
$\mathrm{EXP}_{\mathrm{i}}=$ pengeluaran rutin individu

$\mathrm{AGE}_{\mathrm{i}} \quad=$ usia pengunjung

$\mathrm{EDUC}_{\mathrm{i}}=$ lama pendidikan yang ditamatkan

DSUBT $_{\mathrm{i}}=$ dummy objek wisata pengganti DENVR $_{\mathrm{i}}=$ dummy persepsi kualitas lingkungan objek wisata

$\beta_{0} \quad=$ konstanta

$\beta_{1}, \beta_{2}, \ldots, \beta_{6}=$ koefisien hasil regresi

$\varepsilon_{\mathrm{i}}=$ error term

Sebelum menghitung total nilai ekonomi tahunan, maka perlu diestimasi terlebih dahulu nilai surplus konsumennya. Surplus konsumen merupakan perbedaan antara jumlah total yang bersedia dan dapat dibayar oleh seorang individu untuk mendapatkan suatu barang atau layanan dibandingkan dengan total harga aktual yang dibayarkan (King \& Mazzotta, 2014). Nilai surplus konsumen per kunjungan per individu dapat diestimasi dari negatif inverse koefisien hasil regresi travel cost (Parsons, 2003):

$\widehat{C S}=-\frac{1}{\hat{\beta}_{T C}}$

Sedangkan estimasi total nilai ekonomi tahunan atau aggregate surplus dari objek wisata dapat dihitung dengan mengalikan antara total jumlah kunjungan pada objek wisata dengan surplus konsumen setiap individu per kunjungan (Parsons, 2003).

\section{HASIL DAN PEMBAHASAN Analisis Deskriptif}

Berikut ini merupakan karakteristik data yang diperoleh dari 206 sampel responden. 
Tabel 1.

Karakteristik Sampel Responden

\begin{tabular}{lcc}
\hline & Jumlah Sampel & Persentase Sampel \\
\hline Jenis Kelamin & 116 & 56,31 \\
Laki-laki & 90 & 43,69 \\
Perempuan & & \\
Usia & 109 & 52,91 \\
$18-29$ tahun & 49 & 23,79 \\
$30-39$ tahun & 30 & 14,56 \\
$40-49$ tahun & 18 & 8,74 \\
50 tahun ke atas & & \\
Pendidikan & 1 & 0,49 \\
SD & 27 & 13,11 \\
SMP & 116 & 56,31 \\
SMA/K & 14 & 6,80 \\
Diploma & 48 & 23,30 \\
Sarjana & & \\
Tipe Pengunjung & 31 & 15,05 \\
Lokal & 175 & 84,95 \\
Domestik & & \\
\hline
\end{tabular}

Sumber: Data Primer (diolah)

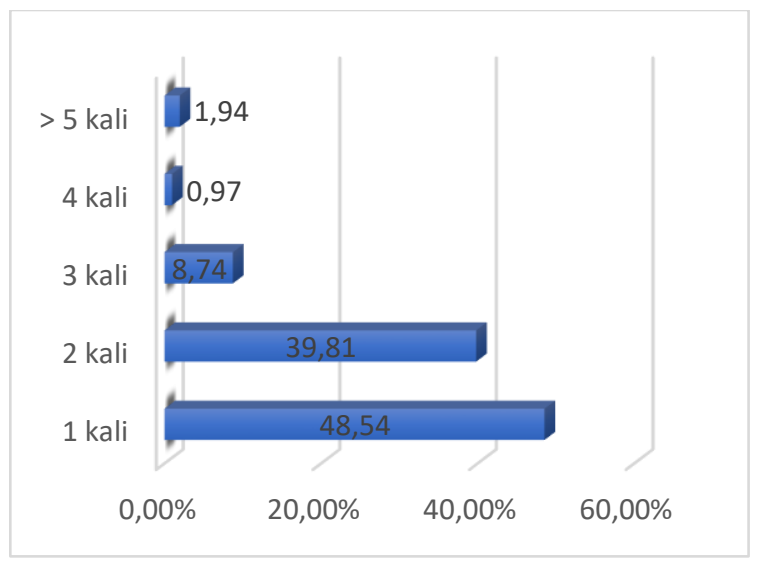

Gambar 1. Karakteristik Responden Berdasarkan Jumlah Kunjungan Sumber: Data Primer (diolah)

Gambar 1 menunjukkan jumlah dan lima kali kunjungan dalam setahun pengunjung yang berwisata ke Kawasan Pantai Baron sebanyak satu kali kunjungan sebanyak 4 orang (1,94 persen).

Pengunjung yang berusia kurang dari 18 dalam setahun sebanyak 100 orang $(48,54$ persen), kemudian dua kali kunjungan tahun tidak dimasukkan dalam sampel dalam setahun sebanyak 82 orang $(39,81$ persen), selanjutnya tiga kali kunjungan dalam setahun sebanyak 23 orang $(11,44$ persen), empat kali kunjungan dalam setahun sebanyak 2 orang (0,97 persen), karena dikhawatirkan tidak dapat menjawab seluruh item pertanyaan dalam kuesioner. Tipe pengunjung lokal merupakan pengunjung yang berasal dari Kabupaten Gunung Kidul sedangkan pengunjung domestik merupakan pengunjung yang berasal dari luar Kabupaten Gunung Kidul. 
Tabel 2.

Ringkasan Statistik Deskriptif

\begin{tabular}{|c|c|c|c|c|c|}
\hline Variable & Mean & Minimum & Maximum & Std. Dev. & Skewness \\
\hline Jumlah kunjungan individu (V) & 1,78641 & 1,00000 & 12,00000 & 1,42555 & 4,94722 \\
\hline $\begin{array}{l}\text { Biaya Perjalanan (TC) (dalam } \\
\text { ratusan ribu) }\end{array}$ & 1,64372 & 0,23000 & 6,50882 & 1,02370 & 1,61147 \\
\hline $\begin{array}{l}\text { Pengeluaran individu } \\
\text { (EXPEND) }\end{array}$ & 21,11650 & 2,00000 & 70,0000 & 13,19677 & 0,95597 \\
\hline \multicolumn{6}{|l|}{ (dalam ratusan ribu) } \\
\hline Lama Pendidikan (EDU) & 12,74272 & 6,00000 & 18,00000 & 2,33673 & 0,14659 \\
\hline Usia (AGE) & 31,35922 & 18,00000 & 64,00000 & 11,33469 & 0,87734 \\
\hline $\begin{array}{l}\text { Dummy Objek Wisata Pengganti } \\
\text { (DSUBT) }\end{array}$ & 0,475728 & 0,00000 & 1,00000 & 0,50063 & 0,09720 \\
\hline $\begin{array}{l}\text { Persepsi Kualitas Lingkungan } \\
\text { (QENVR) }\end{array}$ & 7,85437 & 5,00000 & 10,00000 & 0,80131 & $-0,24572$ \\
\hline
\end{tabular}

Sumber: Data Primer (diolah)

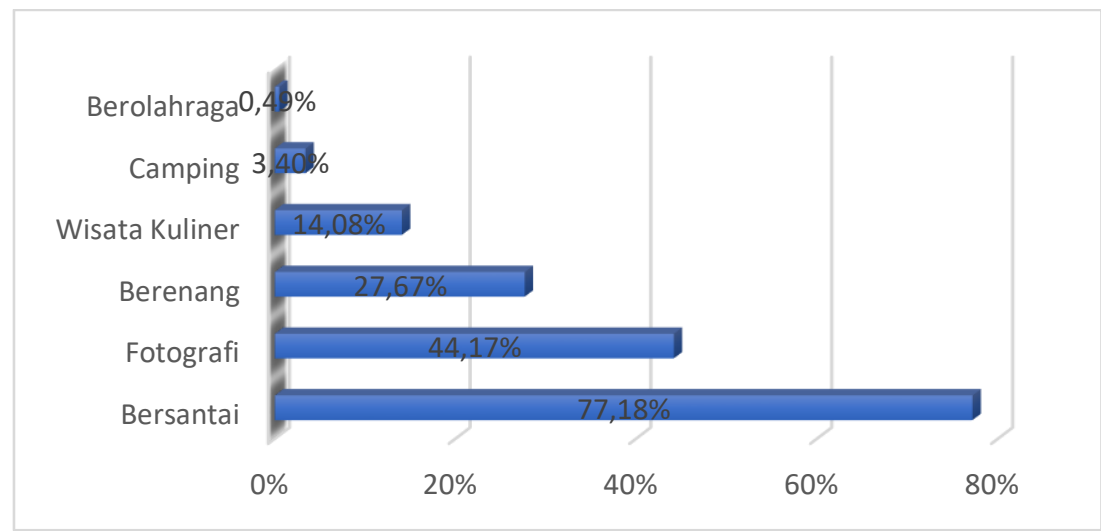

Gambar 2. Aktivitas Selama Berkunjung di Pantai

(Jumlah sampel: 206; responden dapat memilih lebih dari 1 aktivitas)

Sumber: Data Primer (diolah)

Tabel 2 menginformasikan bahwa Kawasan Pantai Baron yaitu jumlah pengeluaran rutin individu terendah bersantai/menikmati keindahan alam, sebesar Rp200.000,00 dan yang tertinggi fotografi, dan berenang. Wisata kuliner, sebesar Rp7.000.000,00. Gambar 2 camping, dan berolahraga juga disukai oleh menunjukkan bahwa aktivitas favorit yang beberapa pengunjung. dilakukan pengunjung selama berada di 


\section{Analisis Inferensia}

Tabel 3.

Output Regresi Poisson

\begin{tabular}{ccl}
\hline Variabel & Koefisien & \multicolumn{1}{c}{ Prob. } \\
\hline Konstanta (C) & 0,113 & 0,867 \\
Biaya Perjalanan (TC) & $-0,385$ & $0,000 * * *$ \\
Pengeluaran individu (EXPEND) & 0,025 & $0,000 * * *$ \\
Lama Pendidikan (EDU) & $-0,020$ & 0,410 \\
Usia (AGE) & $-0,008$ & 0,193 \\
Dummy Objek Wisata Pengganti (DSUBT) & $-0,467$ & $0,000 * * *$ \\
Persepsi Kualitas Lingkungan (QENVR) & 0,151 & $0,033 * *$ \\
R-squared & 0,438 & \\
Adjusted R-squared & 0,421 & \\
Prob(LR statistic) & 0,000 & \\
$* * * \alpha=1 \% \quad * * \alpha=5 \%$ & $* \alpha=10 \%$ & \\
Sumber: Data Primer (diolah) &
\end{tabular}

Dari hasil regresi poisson pada Tabel 3, terdapat 4 (empat) variabel yang secara statistik signifikan yaitu travel cost (TC), pengeluaran (EXPEND), dummy objek wisata pengganti (DSUB), dan persepsi kualitas lingkungan (QENVR) dari 6 (enam) variabel independen yang digunakan dalam model penelitian. Nilai rata-rata dari variabel dependen sebesar 1,786408 dengan standar deviasi sebesar
1.425554. Nilai dari probabilitas likelihood Ratio (LR Statistik) adalah 0,00000 yang bisa diartikan bahwa model secara statistik signifikan pada $\alpha=5$ persen.

Setelah melakukan regresi poisson, langkah selanjutnya yaitu melakukan pengujian apakah model yang digunakan telah memenuhi syarat equidispersi di mana nilai dari mean sama dengan varians. Hasil uji overdispersi yaitu sebagai berikut:

Tabel 4.

Forecast Variabel Dependen untuk Uji Overdispersi

\begin{tabular}{ccc}
\hline Variabel & Koefisien & Prob. \\
\hline $\mathrm{VF}^{\wedge} 2$ & 0,156 & $0,034^{* *}$ \\
Mean dependent var & $-0,650$ & \\
S.D. dependent var & 5,66 & \\
\hline$* * * \alpha=1 \%$ & $* * \alpha=5 \% \quad * \alpha=10 \%$ \\
Sumber: Data Primer (diolah)
\end{tabular}

Berdasarkan Tabel 4 di atas probabilitas untuk koefisien variabel dependen (V) secara statistik signifikan sehingga batasan dari poisson dengan sendirinya ditolak. Uji variabel dependen menghasilkan koefisien yang bernilai positif dan signifikan yaitu
0,156 sehingga mengindikasikan adanya overdispersion dalam residual. Selanjutnya model count data diestimasi kembali dengan menggunakan Negative Binomial Regression. 
Tabel 5.

Output Regresi Negatif Binomial

\begin{tabular}{ccl}
\hline Variabel & Koefisien & Prob. \\
\hline Konstanta (C) & 0,125 & 0,871 \\
Biaya Perjalanan (TC) & $-0,354$ & $0,000 * * *$ \\
Pengeluaran individu (EXPENDITURE) & 0,024 & $0,000 * * *$ \\
Lama Pendidikan (EDU) & $-0,017$ & 0,536 \\
Usia (AGE) & $-0,007$ & 0,267 \\
Dummy Objek Wisata Pengganti (DSUBT) & $-0,449$ & $0,000 * * *$ \\
Persepsi Kualitas Lingkungan (QENVR) & 0,141 & $0,082 *$ \\
R-squared & 0,423 & \\
Adjusted $R$-squared & 0,406 & \\
Prob(LR statistic) & 0,000 & \\
*** $\alpha=1 \% \quad * * \alpha=5 \%$ & $* \alpha=10 \%$ &
\end{tabular}

Sumber: Data Primer (diolah)

Hasil regresi menunjukkan tiga variabel independen yang signifikan pada tingkat alpha $(\alpha) 1$ persen yaitu biaya perjalanan (TC), pengeluaran (EXPEND), dummy objek wisata pengganti (DSUBT) dan variabel persepsi kualitas lingkungan (QENVR) pada tingkat error $10 \%$. Nilai RSquared sebesar 0,423 artinya variasi variabel dependen jumlah kunjungan individu ke objek wisata Kawasan Pantai Baron dapat dijelaskan oleh masing-masing variabel-variabel independen sebesar 42,34\% sedangkan sisanya sebesar $57,64 \%$ dijelaskan oleh variabel lain di luar model.

\section{Interpretasi dan Analisis Ekonomi}

Variabel biaya perjalanan (TC) memiliki pengaruh negatif signifikan secara statistik terhadap jumlah kunjungan individu. Koefisien regresi biaya perjalanan sebesar 0,354 artinya setiap tambahan biaya perjalanan sebesar Rp100.000,00, dengan asumsi variabel lainnya tetap, maka jumlah kunjungan rata-rata yang diharapkan akan berkurang sebesar $100 \times[\exp (-0,354)-1]=$ $29,81 \%$. Hal ini sesuai dengan teori permintaan yang menyatakan bahwa semakin tinggi harga suatu barang dalam hal ini adalah biaya perjalanan yang dikeluarkan individu untuk mengakses situs rekreasi, maka permintaan terhadap barang tersebut akan semakin rendah. Hasil ini sesuai dengan penelitian yang dilakukan oleh Zhang et al., (2015) dan ZambranoMonserrate et al., (2018) yang menyatakan bahwa variabel travel cost berpengaruh negatif terhadap jumlah kunjungan individu ke tempat wisata.

Variabel pengeluaran (EXP) memiliki pengaruh positif signifikan secara statistik terhadap jumlah kunjungan individu. Koefisien regresi pengeluaran sebesar 0,024 artinya setiap tambahan pengeluaran individu sebesar Rp100.000,00, dengan asumsi variabel lainnya tetap, maka jumlah kunjungan rata-rata yang diharapkan akan bertambah sebesar $100 \times[\exp (0,024)-1]=$ $2,43 \%$. Hasil ini sesuai dengan teori ekonomi yang menyatakan bahwa permintaan konsumen akan suatu barang atau jasa tidak hanya dipengaruhi oleh harga barang itu sendiri, tetapi juga oleh variabel lain seperti pendapatan ataupun pengeluaran. Hasil ini sesuai dengan penelitian yang dilakukan oleh (Dewanta, 2010) yang menyatakan bahwa variabel pengeluaran berpengaruh negatif terhadap 
jumlah kunjungan individu ke tempat wisata.

Variabel tingkat pendidikan (EDU) memiliki pengaruh negatif dan tidak signifikan secara statistik terhadap jumlah kunjungan individu. Koefisien regresi tingkat pendidikan sebesar $-0,017$ artinya setiap tambahan tingkat pendidikan sebesar 1 tahun, dengan asumsi variabel lainnya tetap, maka jumlah kunjungan rata-rata yang diharapkan akan berkurang sebesar $100 \times[\exp (-0,017)-1]=1,72 \%$. Hasil ini sesuai dengan penelitian yang dilakukan oleh Zhang et al., (2015), ZambranoMonserrate et al., (2018), dan Shrestha et al., (2002) yang menyatakan bahwa variabel education berpengaruh negatif terhadap jumlah kunjungan individu ke tempat wisata.

Variabel usia (AGE) memiliki pengaruh negatif dan tidak signifikan secara statistik terhadap jumlah kunjungan individu. Koefisien regresi usia sebesar $-0,007$ artinya setiap tambahan usia sebesar 1 tahun, dengan asumsi variabel lainnya tetap, maka jumlah kunjungan rata-rata yang diharapkan akan berkurang sebesar $100 \times[\exp (-0,007)-1]=0,78 \%$. Variabel bernilai negatif ini mengindikasikan bahwa seseorang yang berusia lebih tua kurang tertarik mengunjungi Kawasan Pantai Baron dibandingkan yang berusia lebih muda. Hasil ini sesuai dengan penelitian yang dilakukan oleh Rantelino (2015) dan Pascoe, (2019) yang menyatakan bahwa variabel age berpengaruh negatif terhadap jumlah kunjungan individu ke tempat wisata.

Variabel dummy substitusi objek wisata lain (DS) memiliki pengaruh negatif signifikan secara statistik terhadap jumlah kunjungan individu. Koefisien dummy objek wisata pengganti sebesar $-0,449$ artinya dengan adanya objek wisata lain/pengganti mengurangi jumlah kunjungan rata-rata yang diharapkan sebesar $100 \times[\exp (-0,449)-1]=36,15 \%$. Sesuai dengan teori ekonomi bahwa barang atau jasa pengganti akan mempengaruhi permintaan terhadap barang atau jasa itu. Di mana ketika harga suatu barang atau jasa tertentu naik, maka individu akan mensubstitusikan barang atau jasa tersebut dengan komoditas lainnya yang sejenis (Samuelson \& Nordhaus, 2009). Hasil ini sesuai dengan penelitian yang dilakukan oleh Bulov dan Lugren (2007) yang menyatakan bahwa adanya substitusi tempat wisata berpengaruh negatif terhadap jumlah kunjungan individu ke Taman Nasional Periyar di India.

Variabel dummy kualitas lingkungan (QENVR) memiliki pengaruh positif signifikan secara statistik terhadap jumlah kunjungan individu. Hal tersebut menunjukkan bahwa semakin tinggi kualitas lingkungan, maka semakin tinggi pula jumlah kunjungan individu ke Kawasan Pantai Baron. Koefisien regresi persepsi kualitas lingkungan sebesar 0,141 artinya setiap tambahan penilaian persepsi kualitas lingkungan sebesar 1 satuan, dengan asumsi variabel lainnya tetap, maka jumlah kunjungan rata-rata yang diharapkan akan bertambah sebesar $100 \mathrm{x}$ $[\exp (0,141)-1]=15,10 \%$. Hasil ini sesuai dengan penelitian yang dilakukan oleh Zhang et al., (2015), Zambrano-Monserrate et al., (2018), dan Rantelino (2015) yang menyatakan bahwa variabel kualitas lingkungan berpengaruh positif terhadap jumlah kunjungan individu ke tempat wisata.

\section{Estimasi Nilai Ekonomi}

Sebelum menghitung nilai ekonomi objek wisata Kawasan Pantai Baron perlu 
diketahui dahulu nilai surplus konsumen. Menurut Parsons, (2003) surplus konsumen atau nilai rata-rata per orang per kunjungan dapat diestimasi dengan menggunakan negatif inverse dari koefisien hasil regresi travel cost. Secara matematis rumus tersebut dapat ditulis sebagai berikut:

$$
\widehat{C S}=-\frac{1}{\hat{\beta}_{T C}}
$$

Di mana CS adalah surplus konsumen; dan $\beta_{\text {TC }}$ adalah koefisien hasil regresi dari travel cost.

Hasil perhitungannya yaitu sebagai berikut:

$$
\begin{aligned}
\text { CS } & =\frac{1}{-(-0,354)} \\
& =2,82531 \text { (dalam ratusan ribu rupiah) } \\
& =\mathrm{Rp} 282.531,00
\end{aligned}
$$

Berdasarkan hasil perhitungan di atas, maka diperoleh nilai surplus konsumen atau nilai rata-rata per kunjungan per individu yaitu sebesar Rp282.531,00. Untuk memperoleh total nilai ekonomi tahun dari Kawasan Pantai Baron, maka nilai surplus konsumen tersebut dikalikan dengan estimasi total jumlah kunjungan selama 1 tahun.

Berdasarkan data yang diperoleh dari Dinas Pariwisata Kabupaten Gunung Kidul, jumlah pengunjung di Kawasan Pantai Baron pada tahun 2019 sebanyak 1.982.733 orang. Dengan mengalikan surplus konsumen dengan jumlah pengunjung Kawasan Pantai Baron, maka diperoleh total nilai ekonomi tahunan sebesar Rp560.182.653.564,00 per tahun.

\section{SIMPULAN}

Berdasarkan hasil penelitian yang dilakukan dengan tujuan untuk melakukan estimasi nilai ekonomi Kawasan Pantai Baron dengan TCM, diketahui nilai ekonomi Kawasan Pantai Baron sebesar Rp560.182.653.564,00 per tahun dan surplus konsumen per kunjungan per individu sebesar Rp282.531,00. Dengan mempertimbangkan nilai ekonomi tahunan Kawasan Pantai Baron sebesar Rp560.182.653.564,00, maka kegiatan/ proyek revitalisasi Kawasan Pantai Baron dari ancaman abrasi dan penurunan kualitas lingkungan diperkirakan cukup layak untuk dilaksanakan dari sisi ekonomi.

Terdapat empat variabel yang berpengaruh signifikan yaitu variabel biaya perjalanan, pengeluaran, dummy objek wisata pengganti, dan dummy persepsi kualitas lingkungan (QENVR). Berdasarkan hasil penelitian ini, hal-hal yang dapat disarankan yaitu pihak pengelola dapat bekerja sama dengan biro perjalanan wisata untuk mendapatkan diskon biaya wisata, sehingga biaya perjalanan menjadi lebih murah dan jumlah kunjungan juga dapat meningkat. Pihak pengelola juga dapat bekerja sama dengan investor dalam menciptakan atau mengembangkan wahana rekreasi yang menarik bagi semua kalangan usia pengunjung karena alternatif wisata di Kabupaten Gunung Kidul juga semakin banyak. Pihak pengelola dapat menambah dan merawat kebersihan fasilitas umum seperti spot foto, area untuk berteduh, toilet, serta tempat ibadah untuk meningkatkan kenyamanan bagi pengunjung. Pihak pengelola dapat memanfaatkan media sosial sebagai sarana komunikasi untuk memperkenalkan wisata Kawasan Pantai Baron kepada para wisatawan secara lebih luas. Dalam penelitian selanjutnya diharapkan dapat melakukan penilaian nilai non penggunaan (non-use value) seperti nilai keberadaan Kawasan Pantai Baron. 


\section{DAFTAR PUSTAKA}

Ariza, E., Ballester, R., Rigall-I-Torrent, R., Saló, A., Roca, E., Villares, M., Jiménez, J. A., \& Sardá, R. (2012). On the relationship between quality, users' perception and economic valuation in NW Mediterranean beaches. Ocean and Coastal Management, $63,55-66$.

BPS Gunung Kidul. (2018). Statistik Daerah Kabupaten Gunung Kidul 2018. Badan Pusat Statistik Kabupaten Gunung Kidul.

Bülov, S., \& Lundgren, T. (2007). An Economic Valuation of Periyar National Park. 49.

Dewanta, A. S. (2010). Valuation of Mount Merapi National Park: A Travel Cost Analysis. Economic Journal of Emerging Markets, 2(1), 79-88.

Grogger, J. T., \& Carson, R. T. (1991). Models for Truncated Counts. Journal of Applied Econometrics, Vol. 6, 225-238, 6(3), 225-238.

Haab, T. C., \& McConnell, K. E. (2002). Valuing Environmental and Natural Resources. In New Horizons In Environmental Economics.

King, D. M., \& Mazzotta, M. J. (2014). Ecosystem Valuation. www.ecosystemvaluation.org

Marre, J. B., Thébaud, O., Pascoe, S., Jennings, S., Boncoeur, J., \& Coglan, L. (2016). Is economic valuation of ecosystem services useful to decision-makers? Lessons learned from Australian coastal and marine management. Journal of Environmental Management, 178, 52-62.

Pamungkas, A. H. K. dan A. (2018). Identifikasi Potensi dan Permasalahan Daya Dukung Lingkungan Berdasarkan Aspek Daya Dukung Fisik, Daya Dukung Ekologis, dan Daya Dukung Sosial pada Pantai Baron, Kabupaten Gunung Kidul, Yogyakarta. Jurnal Teknik ITS Vol. 7 No. 1 (2018), 2337-3520 (2301-928X Print), 2337-3520.

Parsons, G. R. (2003). The Travel Cost Model. In a Primer on Nonmarket Valuation. In A Primer on Nonmarket Valuation. Springer, Netherlands.

Pascoe, S. (2019). Recreational beach use values with multiple activities. Ecological Economics, 160(March 2018), 137-144.

Pyndyck, R. S., \& Rubinfeld, D. L. (2013). Microeconomics (Eight Edit). Pearson Education, Inc.

Rantelino, Titik. (2016). Valuasi Ekonomi Objek Wisata Air Umbul Ponggok Kabupaten Klaten Menggunakan Travel Cost Method. Tesis Magister. Fakultas Ekonomika dan Bisnis Universitas Gadjah Mada Yogyakarta.

Samuelson, P. A., \& Nordhaus, W. D. (2009). Microeconomics. In McGraw-Hill Irwin (19th ed.). Douglas Reiner.

Shrestha, R. K., Seidl, A. F., \& Moraes, A. S. (2002). Value of recreational fishing in the Brazilian Pantanal: A travel cost analysis using count data models. Ecological Economics, 42(1-2), 289-299.

Ward, F., \& Beal, D. (2000). Valuing Nature with Travel Cost Models A Manual New Horizons in Environmental Economics. Edward Elgar Publishing, Inc.

Zambrano-Monserrate, M. A., Silva-Zambrano, C. A., \& Ruano, M. A. (2018). The economic value of natural protected areas in Ecuador: A case of Villamil Beach National Recreation Area. Ocean and Coastal Management, 157(March), 193-202.

Zhang, F., Wang, X. H., Nunes, P. A. L. D., \& Ma, C. (2015). The Recreational Value of Gold Coast Beaches, Australia: An Application of the Travel Cost Method. Ecosystem Services, 11, 106-114. 